\title{
Chloride transport and the resulting corrosion of steel bars in alkali activated slag concretes
}

\author{
Qianmin Ma $\cdot$ Sreejith V. Nanukuttan (D) \\ P. A. Muhammed Basheer · Yun Bai • \\ Changhui Yang
}

Received: 29 June 2015/ Accepted: 23 November 2015/Published online: 18 December 2015

(C) The Author(s) 2015. This article is published with open access at Springerlink.com

\begin{abstract}
As the relative performance of alkali activated slag (AAS) concretes in comparison to portland cement (PC) counterparts for chloride transport and resulting corrosion of steel bars is not clear, an investigation was carried out and the results are reported in this paper. The effect of alkali concentration and modulus of sodium silicate solution used in AAS was studied. Chloride transport and corrosion properties were assessed with the help of electrical
\end{abstract}

Q. Ma $\cdot$ S. V. Nanukuttan $(\bowtie)$

School of Planning, Architecture and Civil Engineering, Queen's University Belfast, University Road, BT7 1NN Northern Ireland, UK

e-mail: s.nanukuttan@qub.ac.uk

Q. Ma

Faculty of Civil Engineering and Mechanics, Kunming University of Science and Technology, Jingming South Road, 650500 Kunming, China

P. A. M. Basheer

School of Civil Engineering, University of Leeds, England LS2 9JT, UK

Y. Bai

Department of Civil, Environmental \& Geomatic Engineering, University College London, Gower Street, London WC1E 6BT, UK

C. Yang

College of Material Science and Engineering, Chongqing University, 174 Shapingba Main Street,

Chongqing 400044, China resistivity, non-steady state chloride diffusivity, onset of corrosion, rate of corrosion and pore solution chemistry. It was found that: (i) although chloride content at surface was higher for the AAS concretes, they had lower chloride diffusivity than PC concrete; (ii) pore structure, ionic exchange and interaction effect of hydrates strongly influenced the chloride transport in the AAS concretes; (iii) steel corrosion resistance of the AAS concretes was comparable to that of PC concrete under intermittent chloride ponding regime, with the exception of $6 \% \mathrm{Na}_{2} \mathrm{O}$ and Ms of 1.5; (iv) the corrosion behaviour of the AAS concretes was significantly influenced by ionic exchange, carbonation and sulphide concentration; (v) the increase of alkali concentration of the activator generally increased the resistance of AAS concretes to chloride transport and reduced its resulting corrosion, and a value of 1.5 was found to be an optimum modulus for the activator for improving the chloride transport and the corrosion resistance.

Keywords Alkali activated slag · Chloride diffusivity $\cdot \mathrm{pH}$ profile $\cdot$ Bulk electrical resistivity · Pore solution chemistry $\cdot$ Rate of corrosion

\section{Introduction}

It is widely recognised that an alternative to portland cement (PC) is highly desirable to reduce the high 
carbon footprint of concrete and $100 \%$ of its replacement with alkali activated slag (AAS) is a new environmentally friendly option that could satisfy the strength and durability requirements [1]. However, the physical and durability characteristics of AAS concretes depend on both the physical and chemical characteristics of the slag and the type of activator used [1]. It is known that when sodium silicate solution is used as the activator, the alkali concentration $\left(\mathrm{Na}_{2} \mathrm{O} \%\right)$ and the modulus of the activator (silica modulus, Ms) influence some of the properties of concrete [1]. It has been reported that AAS concretes have a different pore solution composition compared to that of PC [2]. As pore solution composition has a significant influence on chloride transport and resulting corrosion [3, 4], it is essential to understand the influence of the pore solution of AAS concretes on both these characteristics of reinforced concrete so that any potential shortcoming in knowledge for AAS concretes could be addressed.

During the exposure of concrete to a chloride environment, ionic exchanges may significantly influence the diffusion of chloride ions into the concrete mainly from the following aspects:

I. Apart from diffusion of chloride ions from external environment into the concrete, cations accompanying the chloride ions, such as sodium ions, will diffuse into the concrete [5]. Together with the cations originally present in the pore solution of the concrete, they may form a counter electrical field to drag further ingress of chlorides as the mobility of cations is smaller than that of anions [5-7];

II. Ions originally present in the pore solution may also diffuse out to the external environment as a result of the chemical concentration gradient and electro-neutrality constraints [5]. The outward diffusion of hydroxyl ions will empty the sites for chlorides to enter into the concrete to re-occupy the empty sites, thus increasing the amount of chlorides in concrete, especially in the near surface zone [5];

III. Hydrated cement may react with both chlorides and the accompanying cations to slow down further ingress of chlorides $[4,6]$. The orientation and the degree of such interactions are significantly influenced by the surface charge of the hydrated cement (strongly related to the composition of pore solution) and the alkalinity of pore solution $[8,9]$.

As stated previously, AAS has a different pore solution chemistry compared to that of PC. Therefore, the influence of pore solution chemistry on chloride diffusion could be different in the case of AAS compared to PC.

Most research on the chloride resistance of AAS in the past was carried out by using ASTM C 1202 test method [10-12]. Although the results have shown that the AAS had lower charge passed compared to the PC counterpart, it is questionable to use the accelerated electrical test method to evaluate chloride resistance of AAS due to the influence of different pore solution chemistry on the current flow during the accelerated test [1]. Therefore, it is necessary to use a test method similar to that of real chloride exposure environment to study chloride transport in AAS concretes.

Presence of sulphides in pore solution of concrete can significantly reduce the redox potential of the pore solution. Redox potential measurement is a reflection of oxidation and reduction activities [13]. The reduction of the redox potential is a result of the increase of reduction atmosphere, which would protect the embedded steel from its oxidation to a certain extent to reduce the corrosion rate of the steel. Besides, the oxidation of chemically reduced sulphides would form elemental sulphur to deposit in the pores of the damaged passive film allowing the corroded steel to regain passivation [14]. However, Shoesmith et al. [14] suggested that sulphides also play a role to break down the passive film on the surface of steel and then the corrosion of the steel would be initiated. Sulphides are rich in slag, which is why the redox potential of slag cement can be lower than $-400 \mathrm{mV}$ compared to PC, which is normally between 200 and $300 \mathrm{mV}$ [15]. Therefore, it could be anticipated that the corrosion behaviour of the steel in AAS would be different from that in PC. Thus, the main aim of the study reported in this paper was to establish the role of the pore solution of AAS on both the chloride transport and chloride induced corrosion in an experiment that is as close as possible to natural exposure conditions.

Holloway and Sykes [16] and Gomez et al. [17] have studied chloride induced corrosion behaviour of steel embedded in AAS concretes and found that corrosion rate was favourable compared to the PC counterpart. Holloway and Sykes [16] have simulated 
corrosion using internal chlorides, i.e., introduced into the matrix during mixing, whereas Gomez et al. [17] have used continuous immersion. Therefore, in order to have a full picture of the application of AAS concretes to all types of chloride exposures, a severe exposure environment of wetting/drying (chloride ponding) was used in this study. Such a testing regime will simulate the chloride exposures of marine concrete structures under splash and tidal zones and traffic structures under de-icing salt treatment. Besides, due to the influence of the different pore solution chemistry on the electrochemical process, it is also questionable to use an electrochemical method for corrosion rate assessment. Therefore, gravimetric mass loss measurement was used alongside with electrochemical methods to quantify the corrosion rate in this research.

\section{Experimental programme}

A programme of investigation was developed with the objectives of studying: (i) the chloride transport in various AAS concretes; (ii) the subsequent physical and chemical changes to the pore structure and the pore solution; and (iii) the initiation and the propagation of corrosion of embedded steel when these concretes were exposed to an intermittent chloride ponding environment. Full details of the experimental programme shall be given in sub-sections below, but a summary of the experimental variables and the tests shall be given next.

Twelve AAS concretes with alkali concentrations $\left(\mathrm{Na}_{2} \mathrm{O} \%\right.$ of mass of slag) of $4,6,8$ and modulus (Ms) of sodium silicate solution activator of $0.75,1.00$, $1.50,2.00$ were studied. Non-steady state chloride diffusion of these concretes was investigated by using NT BUILD 443 non-steady state chloride diffusion test method [18]. Corrosion of the embedded steel bars was quantified by measuring their gravimetric mass loss after the cyclic chloride ponding test regime. Pore structure and pore solution composition of the concretes were studied in an attempt to explain the physical and chemical changes that occur during the chloride transport and the corrosion. Effects of $\mathrm{Na}_{2} \mathrm{O} \%$ and $\mathrm{Ms}$ on the chloride transport and the corrosion behaviour of the concretes were also investigated.

\subsection{Materials}

Ground granulated blast-furnace slag (GGBS) confirming to BS EN 15167-1:2006 [19] was used to manufacture all the AAS concretes. The GGBS was supplied by Civil and Marine Ltd., UK. Class $42.5 \mathrm{~N}$ PC (CEM-I) conforming to BS EN 197-1: 2000 [20], from Quinn Group Ltd., Northern Ireland, UK was used to manufacture the PC control concrete. The chemical compositions and physical properties of both GGBS and PC are reported in Table 1.

Sodium silicate solution (or commonly known as water glass, WG) with $\mathrm{Na}_{2} \mathrm{O} \%$ of 12.45 and $\mathrm{SiO}_{2} \%$ of 43.60 , which is commercially available as 'Crystal 0503' from Charles Tennant and Co. (NI) Ltd., UK was used as the activator for GGBS. Industrial grade sodium hydroxide powder with a purity of $99 \%$ supplied by Charles Tennant and Co. (NI) Ltd., UK was used to adjust the Ms to the required values.

A barium based retarder 'YP-1 ${ }^{\circledR}[21]$ was used in the AAS concretes to delay the setting time. The retarder was dry-blended with GGBS before mixing. A polycarboxylic polymer based superplasticiser (commercially known as CHEMCRETE HP3 and manufactured by Larsen, Northern Ireland, UK) with a water content of $40 \%$ was used in the PC concrete mix. The water content of the superplasticiser was taken into account whilst determining the mixing water content.

Crushed basalt from local sources in Northern Ireland with size fractions of $20 \mathrm{~mm}$ and $10 \mathrm{~mm}$ combined in a ratio of 1:1 was used as the coarse aggregate. Natural sand with fineness modulus of 2.53 was used as the fine aggregate. Properties of both the fine and coarse aggregates are reported in Table 2. Water from the mains water supply was used to mix and cure concretes.

\subsection{Mix proportions}

Twelve AAS concretes mixes with $\mathrm{Na}_{2} \mathrm{O} \%$ of 4,6 , and 8 and Ms of WG of $0.75,1.00,1.50$ and 2.00 were investigated in this research. The total binder content, which is the sum of GGBS and solid component of the WG, was kept constant at $400 \mathrm{~kg} / \mathrm{m}^{3}$ for all mixes. The water/binder (W/B) ratio was constant at 0.47 for all the AAS concretes. The water content in the WG was taken into account while determining the mixing water 
Table 1 Chemical compositions and physical properties of the GGBS and the PC
Table 2 Specific gravity under saturated surface dry (S. S. D.) condition and 1-h water absorption of the aggregates

\begin{tabular}{|c|c|c|c|c|c|}
\hline \multicolumn{3}{|c|}{ Chemical composition (\%) } & \multicolumn{3}{|l|}{ Physical properties } \\
\hline & GGBS & $\mathrm{PC}$ & & GGBS & $\mathrm{PC}$ \\
\hline $\mathrm{CaO}$ & 39.4 & 61.3 & Specific surface area $\left(\mathrm{m}^{2} / \mathrm{kg}\right)$ & 527 & 386 \\
\hline $\mathrm{SiO}_{2}$ & 34.3 & 23.0 & & & \\
\hline $\mathrm{Al}_{2} \mathrm{O}_{3}$ & 15.0 & 6.15 & Specific gravity $\left(\mathrm{g} / \mathrm{cm}^{3}\right)$ & 2.90 & 3.16 \\
\hline $\mathrm{MgO}$ & 8.00 & 1.80 & & & \\
\hline Sulfide & 0.80 & - & & & \\
\hline $\mathrm{SO}_{3}$ & - & 2.50 & & & \\
\hline $\mathrm{TiO}_{2}$ & 0.70 & - & & & \\
\hline $\mathrm{MnO}$ & 0.50 & - & & & \\
\hline $\mathrm{Na}_{2} \mathrm{O}$ & 0.45 & 0.22 & & & \\
\hline $\mathrm{Fe}_{2} \mathrm{O}_{3}$ & 0.40 & 2.95 & & & \\
\hline $\mathrm{K}_{2} \mathrm{O}$ & 0.38 & 0.68 & & & \\
\hline $\mathrm{Cl}$ & 0.02 & 0.01 & & & \\
\hline Loss on ignition & 0.05 & 1.40 & & & \\
\hline
\end{tabular}

\begin{tabular}{lll}
\hline & Specific gravity (S. S. D.) & 1-h water absorption (\%) \\
\hline 20 mm coarse aggregate & 2.69 & 3.44 \\
$10 \mathrm{~mm}$ coarse aggregate & 2.80 & 2.12 \\
Fine aggregate & 2.73 & 0.75 \\
\hline
\end{tabular}

content. The retarder was added at a dosage of $0.3 \%$ of the mass of GGBS. This dosage of the retarder was found to result in acceptable levels of the setting times of the AAS mixes.

For the purpose of comparison, one PC concrete mix was manufactured with the total binder content as that of the AAS concretes. A W/B ratio of 0.42 was determined for the PC concrete to guarantee its performance in exposure classes XS3 and XD3 as defined in BS EN 206-1:2000 [22]. The use of the superplasticiser of $0.4 \%$ of mass of the cement allowed the PC concrete to just achieve the minimum value of the slump class of $S 2(50 \mathrm{~mm})$ specified in BS EN 206-1:2000 [22]. It may be noted that the W/B ratio of the AAS concretes was 0.47 , not the same as that used for the PC mix. This was essential to ensure that the AAS concretes met the slump requirement. A reduction of W/B ratio to 0.42 for AAS concretes to match with that of PC concrete was found to result in harsh mixes which are not workable. The impact of this on the strength and other properties studied in this research is highlighted in the discussion of results later on in this paper.
The last aspect of the mix design was the ratio of fine aggregate content to total aggregate content. This was kept at $36 \%$ for both the AAS and the PC concretes. Several trials were carried out before arriving at these mix proportions to ensure that the resulting concretes satisfied the specifications for both the exposure classes and the slump class considered.

\subsection{Preparation of samples}

Six $250 \times 250 \times 110 \mathrm{~mm}$ blocks (three with embedded steel bars while the other three had no steel) and nine $100 \times 100 \times 100 \mathrm{~mm}$ cubes for each mix were cast for the tests to be detailed in Sect. 2.4. Figure 1 shows the concrete blocks with embedded steel bars. Also shown in this figure are the stainless steel bars (hereafter referred to as electrodes) used for measuring the electrical resistivity of the concretes during the cycling ponding/drying regime. The top bar served as the anode and the three bottom bars together acted as the cathode for electrochemical corrosion measurements. Before embedding the steel bars, they were cleaned first with a wire brush and then with a dry 


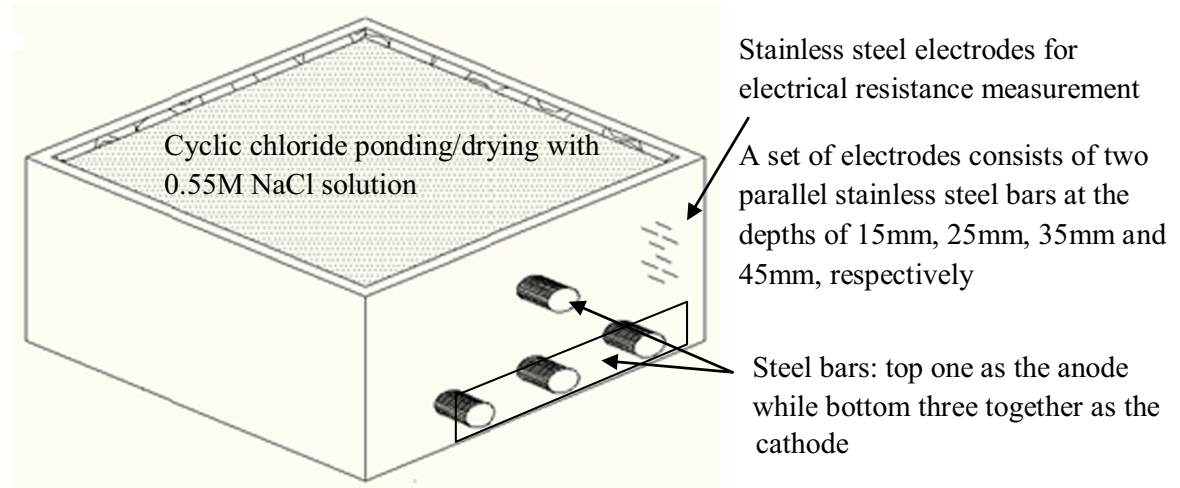

Fig. 1 Diagrammatic representation of the concrete block for the corrosion tests

cleaning cloth to remove any rust and debris, at which stage they were weighed.

As shown in Fig. 1, the stainless steel electrodes were embedded at four different depths, viz. 15, 25, 35 and $45 \mathrm{~mm}$, from the ponding surface in a staggered arrangement to facilitate the distribution of both coarse and fine aggregates around the electrodes. The electrodes were sleeved for the whole length with a heat-shrink tube except for a middle region of $50 \mathrm{~mm}$ before embedding in the blocks so that any change in electrical resistance measured from the pair of electrodes would be due to the changes in the middle region.

Both the blocks and the cubes were cast by following the procedure given in BS 1881-125:1986 [23]. After mixing, the fresh concrete was transferred into the moulds in two layers. Each layer was compacted by placing the moulds on a vibrating table until no air bubbles appeared on the surface of the concrete. The surface of the concrete was finished by a metal float. After casting, moulds were covered with thin polythene sheets to minimise evaporation of water from the surface of concrete. Approximately $1 \mathrm{~h}$ after the concrete surface became stiff, the moulds were covered with a layer of previously wetted hessian and then covered with a layer of polythene sheet. The samples were stored in this condition for 3 days. The hessian was maintained in moisture condition at every $6 \mathrm{~h}$. At the end of this period, the concrete specimens were demoulded, wrapped in wet hessian and plastic bags and stored in a constant temperature room at $20 \pm 1{ }^{\circ} \mathrm{C}$ for 91 days. The hessian was checked for the moisture condition at every 2 weeks and rewetted if needed.
The whole procedure of sample preparing described above was kept same for both the AAS and the PC concretes.

\subsection{Test procedures}

\subsubsection{Slump and compressive strength}

The slump test specified in BS EN 12350-2:2009 [24] was carried out on the fresh concretes and the results are presented in Table 3. The compressive strength test according to BS EN 12390-3:2009 [25] was carried out on the $100 \mathrm{~mm}$ cubes at 3,28 and 91 days of age. The compressive strength results reported in Table 3 are the average values from three cubes.

\subsubsection{Chloride diffusivity}

In order to understand chloride transport in the AAS concretes similar to the real exposure environment, non-steady state chloride diffusion test in accordance with NT BUILD 443 [18] was carried out on the concretes. One day before the test age of 91 days, three cores of diameter $100 \mathrm{~mm}$ per mix were cored from the three $250 \times 250 \times 110 \mathrm{~mm}$ concrete blocks containing no steel bars. A slice with a thickness of $50 \mathrm{~mm}$ from the casting surface (trowel finished face) was cut off, the rest was kept for carrying out the test. The vacuum saturation regime similar to that of NT BUILD 492 [26] was used to precondition the cores. In NT BUILD 492 after the application of the vacuum, saturated $\mathrm{Ca}(\mathrm{OH})_{2}$ solution is introduced into the container. However, it was considered that this is likely to lead to leaching of ions from the samples. 
Table 3 Slump and compressive strength ( \pm standard deviation) of $0.3 \%$ by mass of slag was used for AAS mixes while superplasticiser of $0.5 \%$ by mass of cement was used for PC mix) the concretes (retarder of

\begin{tabular}{|c|c|c|c|c|}
\hline \multirow[t]{2}{*}{ Mix No. $\left(\mathrm{Na}_{2} \mathrm{O} \%-\mathrm{Ms}\right)$} & \multirow[t]{2}{*}{ Slump (mm) } & \multicolumn{3}{|c|}{ Compressive strength (MPa) } \\
\hline & & $3 \mathrm{~d}$ & $28 \mathrm{~d}$ & $91 \mathrm{~d}$ \\
\hline $4 \%-0.75$ & 55 & $22.3 \pm 0.1$ & $44.7 \pm 0.2$ & $46.4 \pm 1.0$ \\
\hline $4 \%-1.00$ & 55 & $21.8 \pm 0.1$ & $46.7 \pm 1.0$ & $55.6 \pm 0.6$ \\
\hline $4 \%-1.50$ & 55 & $1.7 \pm 0.0$ & $49.5 \pm 0.2$ & $52.6 \pm 2.3$ \\
\hline $4 \%-2.00$ & 55 & $1.4 \pm 0.0$ & $33.3 \pm 0.4$ & $44.1 \pm 0.1$ \\
\hline $6 \%-0.75$ & 65 & $31.7 \pm 0.7$ & $47.3 \pm 0.0$ & $51.8 \pm 2.4$ \\
\hline $6 \%-1.00$ & 65 & $37.3 \pm 0.2$ & $53.6 \pm 0.0$ & $59.1 \pm 0.8$ \\
\hline $6 \%-1.50$ & 65 & $20.3 \pm 0.7$ & $60.8 \pm 0.1$ & $67.4 \pm 2.6$ \\
\hline $6 \%-2.00$ & 75 & $8.0 \pm 0.0$ & $59.6 \pm 0.2$ & $68.7 \pm 2.1$ \\
\hline $8 \%-0.75$ & 70 & $32.3 \pm 0.0$ & $51.9 \pm 0.1$ & $56.2 \pm 0.2$ \\
\hline $8 \%-1.00$ & 105 & $32.7 \pm 2.4$ & $53.6 \pm 0.1$ & $67.1 \pm 0.6$ \\
\hline $8 \%-1.50$ & 145 & $34.1 \pm 0.7$ & $59.3 \pm 3.2$ & $70.5 \pm 2.5$ \\
\hline $8 \%-2.00$ & 180 & $11.7 \pm 0.2$ & $55.4 \pm 0.2$ & $65.0 \pm 0.8$ \\
\hline $\mathrm{PC}$ & 50 & $35.4 \pm 1.2$ & $58.9 \pm 1.8$ & $66.3 \pm 2.3$ \\
\hline
\end{tabular}

\subsubsection{Corrosion of the embedded steel bars}

Therefore, in this research, after the application of the vacuum, the vacuum was released, samples were wrapped in deionised water saturated hessian and placed back in the container. The vacuum was again applied. The purpose of this change in saturation regime was to prevent calcium hydroxide solution used for saturation affecting the pore solution chemistry of the concrete samples as well as to minimise the loss of ions from the concrete samples. After conditioning to a surface-dry condition, an epoxy resin was applied onto the surfaces of the specimens in three layers except the test surface (mould finish surface). When the epoxy coating was dry, the cores were immersed for 3 months in a $\mathrm{NaCl}$ solution for which the concentration was $165 \mathrm{~g} / \mathrm{l}(\approx 2.82 \mathrm{M})$. After the immersion, the cores were profile ground to obtain concrete dust from different depths at an increment of $3 \mathrm{~mm}$ up to a depth of $30 \mathrm{~mm}$ from the exposed surface. The total chloride content of the dust samples was determined in accordance with RILEM TC 178-TMC recommendations [27] using pre-calibrated potentiometric titration method. Meanwhile, the concrete dust was dissolved in deionised water in accordance with RILEM TC 178-TMC recommendations [28] to measure $\mathrm{pH}$ value of the suspension. Chloride diffusivity and chloride content at the surface of the concrete samples were determined by using Fick's second law of diffusion, as described in NT BUILD 443 [18].
One month before the test age of 91 days, the three concrete blocks with the embedded steel bars (see Fig. 1) were conditioned at a constant temperature of $23( \pm 3){ }^{\circ} \mathrm{C}$ and relative humidity of around $55 \%$ for a duration of 2 weeks. The epoxy resin was applied onto all of the surfaces of the blocks in three layers except the ponding surface and the surface opposite to the ponding surface. The blocks were then stored at the above condition for another 2 weeks. During the whole conditioning and testing periods, the blocks were supported by two timber strips with thickness of above $13 \mathrm{~mm}$ to allow air flow under the blocks. Approximately $200 \mathrm{ml}$ of $\mathrm{NaCl}$ solution with concentration of $0.55 \mathrm{M}(\approx 31.85 \mathrm{~g} / \mathrm{l})$ was used to pond the blocks for 1 day followed by 6 days for drying. This cycle of intermittent chloride intermittent ponding was continued until the end of the test $(250+$ days $)$. Before each ponding cycle, the electrical resistance of the concrete cover was measured at the depths of 15 , 25,35 and $45 \mathrm{~mm}$ from the surface of the concrete block with the help of embedded stainless steel electrodes shown in Fig. 1. At the end of the test, the blocks were split opened, the anodic steel bars were taken out, scrubbed with wire brush, wiped with a dry cloth and weighed to determine the mass loss caused by the corrosion. The corrosion rate $(\mathrm{mm} / \mathrm{year})$ of the steel bars was calculated using the following equation: 
corrosion rate $\left(\frac{m m}{\text { year }}\right)=\frac{1000 \times \mathrm{m}}{A \times t \times \rho}$

where $m$ is the mass loss in gram, $\rho$ is the density of steel of $7.87 \mathrm{~g} / \mathrm{cm}^{3}, A$ is the complete surface area of the steel attacked by corrosion in $\mathrm{mm}^{2}$ and $t$ is the test duration in year.

\subsubsection{Pore solution expression and bulk electrical resistivity}

One day before the test age of 91 days, cores with diameter of $60 \mathrm{~mm}$ were cut from the $250 \times 250 \times 110 \mathrm{~mm}$ concrete blocks containing no steel bars. A slice with a thickness of $10 \mathrm{~mm}$ from the casting surface (trowel finished face) was cut off. The pre-saturation procedure described in Sect. 2.4.2 was carried out on the cores. The pore solution within the cores was extracted by using a specialist pore fluid expression device when the cores were subjected to pressures up to 300 tonnes. Once the solution was collected, $\mathrm{pH}$ and conductivity of the solution were measured immediately by using a $\mathrm{pH}$ meter and a conductivity meter, respectively. The concentration of $\mathrm{Na}^{+}, \mathrm{Ca}^{2+}, \mathrm{Mg}^{2+}, \mathrm{Al}^{3+}, \mathrm{Si}^{4+}$ and $\mathrm{S}^{2-}$ in the solution was analysed subsequently by using an inductively coupled plasma-optical emission mass spectrometer (ICP-MS) technique. The concentration of $\mathrm{Na}^{+}$and $\mathrm{S}^{2-}$ is discussed in this paper due to their specific relevance to the topic of this paper. However, the full data on the concentration of the other ions are available somewhere else [29].

Before the non-steady state chloride diffusion test, the bulk electrical resistivity of the cores was determined by using a method described in the Chlortest report [30], which is considered to indicate the pore structure of the concrete.

\section{Results and discussion}

\subsection{Slump and compressive strength}

The slump values of the concretes show that all the mixes had a slump value greater than $50 \mathrm{~mm}$. The principle of mix design for the AAS concretes consisted of using a fixed W/B ratio whilst meeting the minimum slump requirement for their use in chloride environments, such as S2 specified in BS
8500-1:2006 [31] for marine environments. The mix design for the PC reference concrete also followed the same principle. Therefore, it can be seen that the slump results of all the 13 mixes met the minimum requirement for $\mathrm{S} 2$ slump class, which is $50 \mathrm{~mm}$.

It is also found that the slump values of the AAS concretes increased with the increase of $\mathrm{Na}_{2} \mathrm{O} \%$. This is in agreement with the results reported by Allahverdi et al. [32] and Karahan and Yakupoglu [33]. The plasticising effect provided by $\mathrm{Na}_{2} \mathrm{O}$ component is considered to be responsible for this [32].

Ms had no significant influence on the slump of the AAS concretes until $\mathrm{Na}_{2} \mathrm{O} \%$ was increased to $8 \%$, and the slump increased with the increase of Ms when $\mathrm{Na}_{2} \mathrm{O} \%$ was $8 \%$. With the increase of $\mathrm{Ms}$, the increase of $\mathrm{SiO}_{2}$ component in WG increases the viscosity of WG and then decreases the slump of AAS concrete. However, total liquid content in AAS concrete (WG $+\mathrm{NaOH}+$ additional water) also increases with the increase of Ms to increase the slump of AAS concrete. When a high $\mathrm{Na}_{2} \mathrm{O} \%$ was applied, with the increase of Ms, the increase rate of total liquid content was significantly higher than that of $\mathrm{SiO}_{2}$ component, which, consequently, results in the increase of the slump of the AAS concretes.

The compressive strength of the concretes at the ages of 3, 28 and 91 days of age reported in Table 2 shows that the presence of the retarder had some detrimental effect on compressive strength in the case of AAS concretes, particularly at the age of $3 \mathrm{~d}$. The mix design for the PC reference concrete was to meet the requirement for XS3 and XD3 exposure environments specified in BS EN 206-1:2000 [22]. From the compressive strength results at the age of 28 days it can be seen that not all the AAS concretes achieved the required strength of $58 \mathrm{MPa}$ for the two exposure classes. However, most of the AAS concretes met the strength requirement of $50 \mathrm{MPa}$ for the exposure classes XS1, XD1 and XD2. It should be noted that the W/B ratio used for the AAS concretes (0.47) was higher than that for the PC concrete (0.42). Therefore, an improved compressive strength could be expected if a lower W/B ratio was used for the AAS concretes. However, this would require the development of a superplasticiser that works with AAS to improve the workability.

The increase of $\mathrm{Na}_{2} \mathrm{O} \%$ generally increased the compressive strength of the AAS concretes, which is in agreement with the results reported by the others 
$[12,34]$. The amount of C-S-H generated in AAS increases with the increase of $\mathrm{Na}_{2} \mathrm{O} \%$ [35]. This may be responsible for the increased compressive strength.

The AAS concretes with Ms of 1.50 generally obtained the highest compressive strength, which has a good agreement with the results reported previously $[34,36]$. This could be attributed in that the best hydration of AAS is usually obtained when Ms is around $1.50[34,36]$.

\subsection{Chloride diffusivity, pore structure and binding}

The non-steady state chloride diffusion coefficient $\left(D_{\text {nssd }}\right)$ of the AAS concretes is compared with that of the PC concrete in Fig. 2. Here it can be seen that the $D_{\text {nssd }}$ of the former was much lower than of the latter despite the higher W/B ratio used in the former. This suggests that the AAS concretes offer better resistance to chloride ingress. In the paragraph below a detailed assessment of the data is carried out and an explanation is provided for this observation.

The bulk electrical resistivity of the concretes was measured in an attempt to indicate the pore structure of the concretes and to further explain the $D_{\text {nssd }}$ results. It is known that electrical resistivity measurements are significantly influenced by the pore solution conductivity of the concrete and, therefore, the bulk resistivity alone cannot be used to represent the pore structure of concretes [37, 38]. Consequently, the pore solution conductivity of the concretes was also measured and its reciprocal (pore solution resistivity) was plotted alongside the bulk electrical resistivity, as presented in

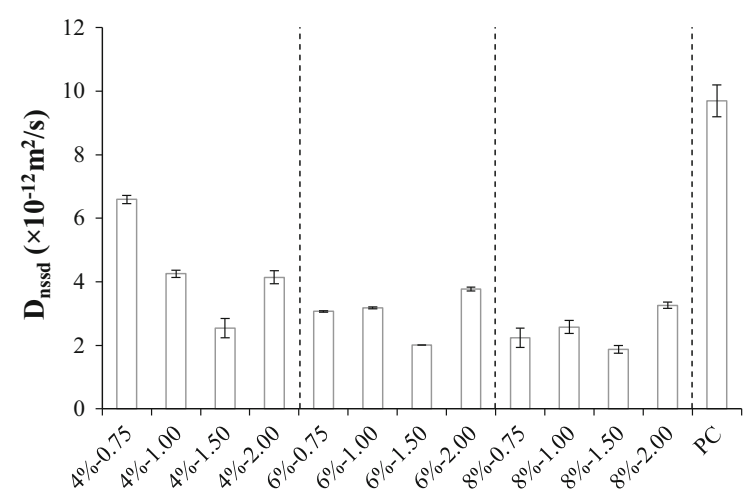

Fig. 2 Non-steady state chloride diffusion coefficients of the concretes
Fig. 3. This figure shows that the AAS concretes had lower pore solution resistivity than the PC concrete owing to the highly ionic nature of the former. Therefore, according to the model proposed by Whittington et al. [39], the reason for the higher bulk resistivity of the AAS concretes, which is in agreement with the results reported by Rodriguez et al. [11], could be attributed to their denser tortuous pore structure and/or their lower conductive binder matrix. When the pore solution is highly ionic and conductive (i.e. poorly resistive), the conductivity of binder matrix will be insignificant (under normal circumstances). This suggests that there would be more ionic flow taking place through the pore solution and the binder plays an insignificant role in the overall electrical resistivity. In Fig. 2, despite the AAS concretes being less resistive compared to the PC counterpart (as per Fig. 3), they exhibited lower chloride diffusivity. This can happen only if the pore structure is very dense and tortuous $[10,11]$. That is, it can be inferred that the relative better chloride diffusivity of AAS concrete is the result of their improved microstructure of the solid phases.

C-S-H (type I), C-A-S-H and hydrotalcite are the main hydration products in AAS [40] and they have much potential to bind alkali cations [41, 42]. Substantial amount of $\mathrm{Na}^{+}$had been introduced into the AAS concretes at the beginning of the mixing (for instance, Puertas et al. [2] report that the concentration of $\mathrm{Na}^{+}$was $60,000 \mathrm{ppm}$ in the AAS paste at the age of $3 \mathrm{~h}$ when WG with $\mathrm{Na}_{2} \mathrm{O} \%$ of 4 was used). However, after 3 months of curing, a dramatic reduction in the

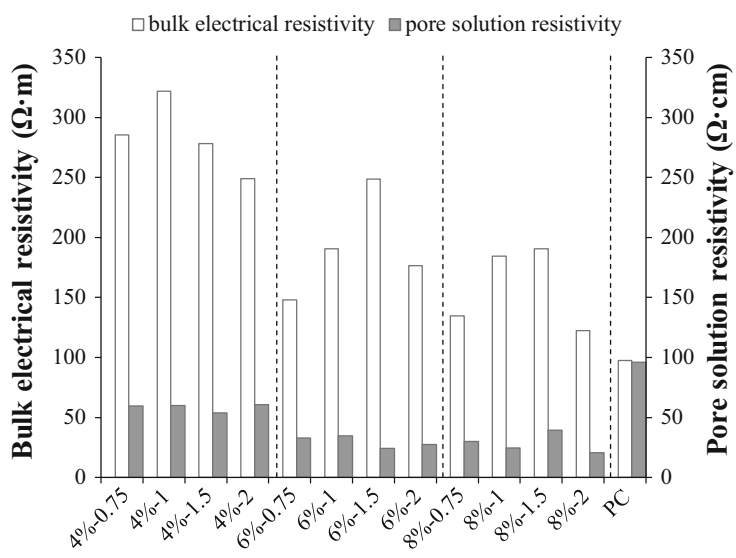

Fig. 3 Bulk and pore solution electrical resistivity of the concretes 
concentration of free $\mathrm{Na}^{+}$was observed in the AAS concretes, as reported in Table 4 . This would suggest that during the transport of chlorides, there is a potential for significant binding of the accompanying sodium cations by the hydrates to occur in the AAS concretes. Such binding could retard the further ingress of chlorides in such concretes and reduce their chloride diffusivity [6]. The lower $\mathrm{pH}$ for the AAS concretes (refer to Table 4) could also have enhanced their chloride binding capacity due to a competition in absorption between $\mathrm{Cl}^{-}$and $\mathrm{OH}^{-}$[9], which also could reduce the $\mathrm{D}_{\text {nssd }}$.

However, it is observed in Fig. 4 that the total chloride content at the surface of the AAS concretes was higher than that of the PC concrete. It is considered that the greater ionic exchange between $\mathrm{Cl}^{-}$and $\mathrm{OH}^{-}$could be the reason for this. Figure 5 presents $\mathrm{pH}$ profiles of the concretes after the chloride diffusion test. It is clear to see that the $\mathrm{pH}$ values decreased dramatically in the near surface zone of the AAS concretes. Outward diffusions of alkali materials from the concrete into the chloride source solution during the test could be the reason for the $\mathrm{pH}$ reduction, where $\mathrm{OH}^{-}$is considered to be the main contributor [43]. When such outward diffusion occurs in $\mathrm{PC}$ concrete, $\mathrm{Ca}(\mathrm{OH})_{2}$ would dissolve in the pore solution to buffer its alkalinity [44]. This explains the reason for a constant $\mathrm{pH}$ value in the $\mathrm{PC}$ concrete at

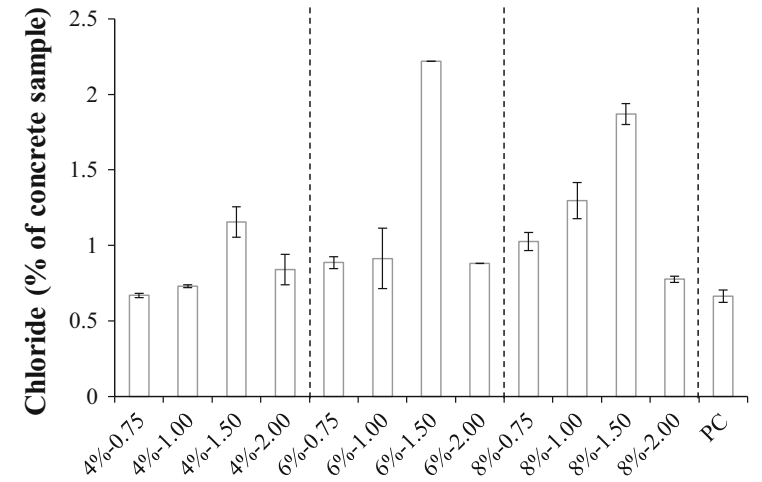

Fig. 4 Mathematically determined surface chloride concentration of the concretes

different depths. However, $\mathrm{Ca}(\mathrm{OH})_{2}$ is not one of the hydration products of AAS. Without the buffering effect, the loss of alkalinity would be more severe in the case of the AAS concretes, particularly in the near surface zone. As a result, it can be considered that more chlorides penetrated into the near surface zone of the AAS concretes to take the sites originally occupied by $\mathrm{OH}^{-}$. Besides, any possible chloride binding provided by hydration products of the AAS concretes, such as C-S-H (I), C-A-S-H and hydrotalcite, could also increase the amount of chlorides at the surface of such concretes.

Table $4 \mathrm{pH}$, conductivity and composition of the pore solution of the concretes after 3 months of curing and chloride contents of the concretes at anodic steel bar level after the corrosion test (\% by mass of concrete sample)

\begin{tabular}{|c|c|c|c|c|c|c|}
\hline \multirow{2}{*}{$\begin{array}{l}\text { Mix no. } \\
\left(\mathrm{Na}_{2} \mathrm{O} \%-\mathrm{Ms}\right)\end{array}$} & \multirow[t]{2}{*}{$\mathrm{pH}$} & \multirow{2}{*}{$\begin{array}{l}\text { Conductivity } \\
(\mathrm{mS} / \mathrm{cm})\end{array}$} & \multicolumn{2}{|c|}{ Concentration of ions (ppm) } & \multicolumn{2}{|l|}{$\mathrm{Cl}$} \\
\hline & & & $\mathrm{Na}$ & $\mathrm{S}$ & Total & Water soluble \\
\hline $4 \%-0.75$ & 11.7 & 16.8 & 2154 & 2458 & 0.45 & 0.31 \\
\hline $4 \%-1.00$ & 11.9 & 16.7 & 4740 & 1953 & 0.44 & 0.21 \\
\hline $4 \%-1.50$ & 10.5 & 18.6 & 58.96 & 3786 & 0.45 & 0.19 \\
\hline $4 \%-2.00$ & 9.9 & 16.5 & 121.2 & 4348 & 0.54 & 0.20 \\
\hline $6 \%-0.75$ & 11.9 & 30.5 & 96.26 & 5661 & 0.40 & 0.19 \\
\hline $6 \%-1.00$ & 11.9 & 28.9 & 69.19 & 6210 & 0.34 & 0.17 \\
\hline $6 \%-1.50$ & 11.4 & 41.0 & 42.81 & 6245 & 0.28 & 0.16 \\
\hline $6 \%-2.00$ & 9.9 & 36.6 & 18.20 & 6292 & 0.34 & 0.20 \\
\hline $8 \%-0.75$ & 12.4 & 33.3 & 202.0 & 664.0 & 0.45 & 0.15 \\
\hline $8 \%-1.00$ & 12.2 & 40.7 & 244.0 & 590.0 & 0.46 & 0.20 \\
\hline $8 \%-1.50$ & 10.8 & 25.5 & 185.3 & 618.3 & 0.45 & 0.23 \\
\hline $8 \%-2.00$ & 11.9 & 48.6 & 64.34 & 608.0 & 0.44 & 0.26 \\
\hline $\mathrm{PC}$ & 12.5 & 10.4 & 1234 & 329.6 & 0.41 & 0.20 \\
\hline
\end{tabular}




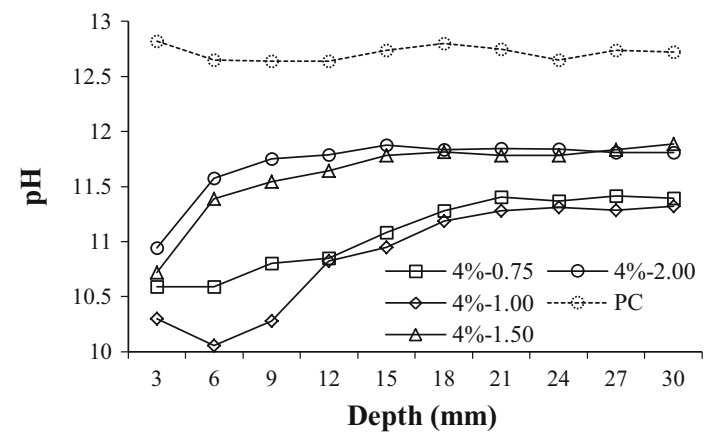

(a)

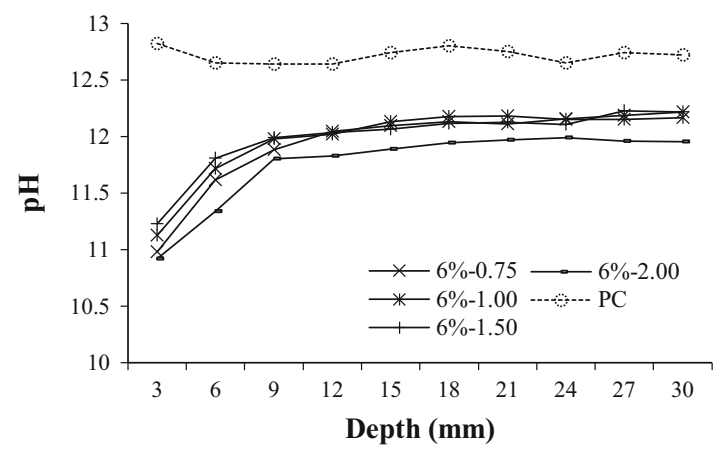

(b)

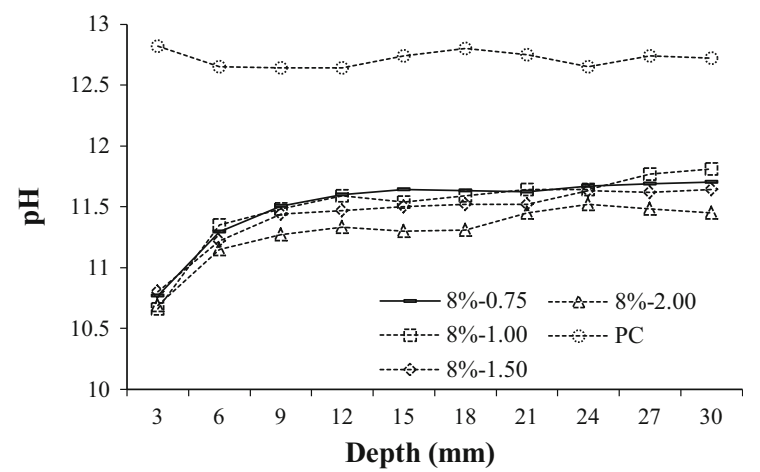

(c)

Fig. $5 \mathrm{pH}$ profiles after 3 months of chloride immersion

The $D_{\text {nssd }}$ of the AAS concretes decreased with the increase of $\mathrm{Na}_{2} \mathrm{O} \%$ from 4 to 8 , as shown in Fig. 6. As reported by Al-Otaibi [12] and Karahan and Yakupoglu [33], porosity of AAS is reduced with the increase of $\mathrm{Na}_{2} \mathrm{O} \%$. This could be one of the primary reasons for the reduction in $D_{\text {nssd }}$ with the increase of $\mathrm{Na}_{2} \mathrm{O} \%$ for the AAS concretes. Besides, hydration degree of AAS increases with the increase of $\mathrm{Na}_{2} \mathrm{O} \%$ [35]. As a result, more hydration products would be formed in the AAS with a higher $\mathrm{Na}_{2} \mathrm{O} \%$, increasing the binding capacity of either/both chlorides and/or

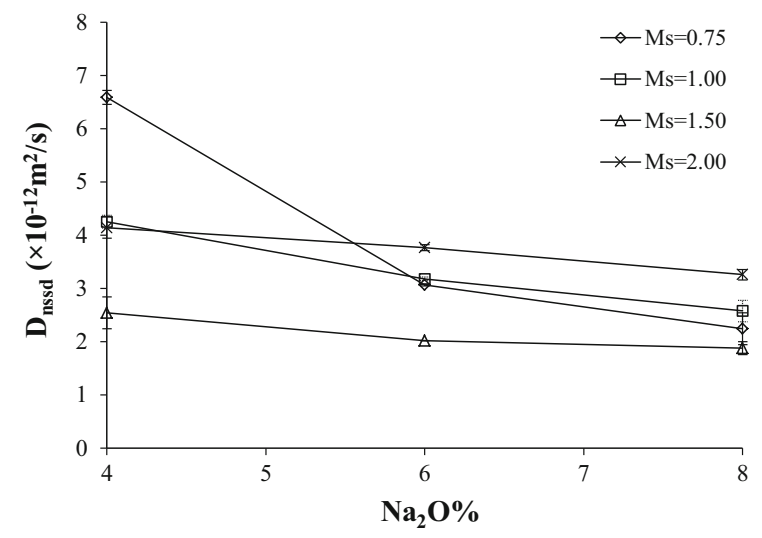

Fig. 6 Effect of $\mathrm{Na}_{2} \mathrm{O} \%$ on the non-steady state chloride diffusion coefficient

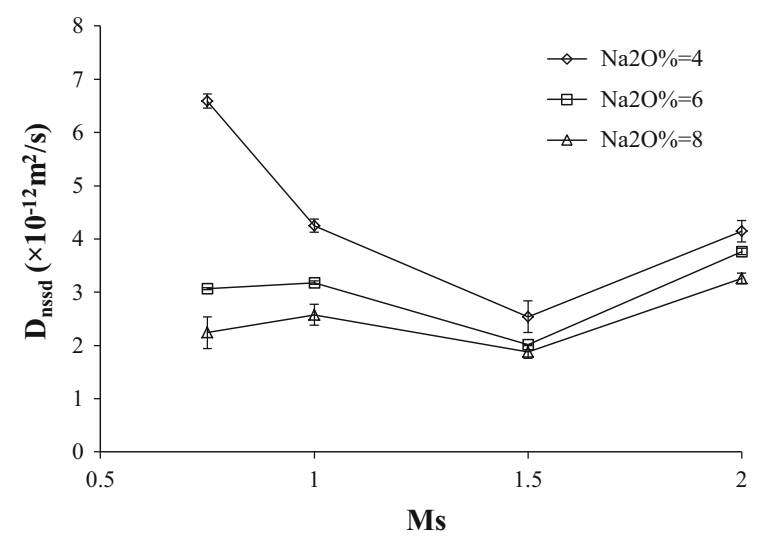

Fig. 7 Effect of Ms on the non-steady state chloride diffusion coefficient

their accompanying sodium cations. This could also have contributed to the reduction of $D_{\text {nssd }}$ in AAS concretes with the increase of $\mathrm{Na}_{2} \mathrm{O} \%$.

Ms around 1.50 is optimum for the hydration of AAS $[34,36]$. As a result, the reduced porosity and enhanced binding capacity of AAS with Ms around 1.50 could be the reasons for the lowest $D_{\text {nssd }}$ provided by the AAS concretes with Ms of 1.50, as shown in Fig. 7.

\subsection{Corrosion of the embedded steel}

As discussed previously, the AAS concretes may have better pore structure than the PC concrete. Consequently, the former had lower chloride diffusivity. From Table 4 it can be seen that although the duration 
of intermittent chloride ponding was much longer for the AAS concretes (427-588 days), compared to the PC concrete (245 days), both total and water soluble chloride contents at the anodic steel bar level were generally comparable between the AAS and the PC concretes at the end of the chloride ponding regime. Similarly, their resistance to the ingress of the other aggressive substances such as water and $\mathrm{O}_{2}$ may also be favourable and a low corrosion rate of the embedded steel bars was anticipated. However, the corrosion rate of the steel bars in the AAS concretes was not significantly lower than that of the PC concrete, as shown in Fig. 8. The corrosion rates reported in Fig. 8 are the average values from three specimens. It is apparent from the figure that some AAS $\left(6 \% \mathrm{Na}_{2} \mathrm{O}\right)$ performs well in terms of mass loss (and therefore rate) despite the increased exposure duration. This will be discussed in further sections where the influence of $\mathrm{Ms}$ and $\mathrm{Na}_{2} \mathrm{O}$ are considered.

Figure $8 \mathrm{~b}$ shows the picture of corroded steel bars from few AAS and PC concretes. It can be seen that the steel bars in the AAS concretes were corroded significantly with most of the steel surface area covered in corrosion products and occasional pits can be seen. However, due to the different chloride ponding durations, the condition of the steel bars could not be compared between the AAS and the PC concretes. It should be noted here that the steel bars were cleaned before being embedded in the concretes. Consequently, during the preconditioning stage i.e., before the chloride ponding, corrosion could have started. Therefore, the corrosion rates reported in Fig. 8 is probably the sum of the rates before and after the chloride ponding. However, for the purpose of comparison amongst different mixes and owing to the fact that all steel bars went through the same preparation procedure, the corrosion caused by the preconditioning is ignored in discussions.

The reason for the trivial improvement in performance of the steel bars in the AAS concretes could be attributed to the outward diffusion of ions from the concrete cover into the exposure solution during the intermittent chloride ponding. It is considered that the outward diffusion of alkali materials may have resulted in the reduction of the $\mathrm{pH}$ values in the concrete cover (see Fig. 9). Without the buffering of $\mathrm{Ca}(\mathrm{OH})_{2}$ in the AAS concretes, the continuous diffusion could have resulted in the dissolution of the binder from the cover concrete. Besides, carbonation may have occurred during the drying period, which could also have resulted in the disintegration of the binder of the concrete cover. This is particularly valid for AAS concrete [12]. From the electrical resistance results of the cover concrete (shown in Fig. 10) it can be seen that, unlike the PC concrete, the electrical resistance of the AAS concretes at the first layer generally increased at the slowest rate compared to the electrical resistance at the other depths. This confirms the poor condition of the surface of the AAS concretes.

From Fig. 11 it can be seen that except AAS concretes with Ms of 2.00, the corrosion rate of the steel bars in the AAS concretes decreased with the increase of $\mathrm{Na}_{2} \mathrm{O} \%$ from 4 to 6 , and then was nearly constant when the $\mathrm{Na}_{2} \mathrm{O} \%$ increased further to 8 . Pore structure of AAS becomes better with the increase of $\mathrm{Na}_{2} \mathrm{O} \%[12,33]$ to resist the ingress of the aggressive substances. The steel bars in the AAS concretes with $6 \% \mathrm{Na}_{2} \mathrm{O}$ generally gave the lowest corrosion rate as shown in Fig. 12 and the modulus, Ms of 1.50, seems influential in mitigating corrosion effects. Both the higher sulphides concentration and the lower $D_{\text {nssd }}$ could have contributed to the lower corrosion rate.

\subsection{Relationship between the chloride diffusivity and the steel corrosion rate}

It was expected that corrosion rate of the embedded steel bars would decrease with the reduction of chloride diffusivity. However, such correlation does not exist for the AAS concretes, as shown in Fig. 13. The possible reasons for the lack of any correlation are as follows: (1) in addition to chloride diffusivity, corrosion rate of the embedded steel in concrete is also dependent on the availability of oxygen and water, and concentration of sulphides in the pore solution of the concrete; and (2) absorption occurs in the chloride intermittent ponding regime which is not the case for the immersion test and consequently the chloride transport in these two cases will be different. The disintegration of the binder at the surface of the AAS concretes may also have contributed to such a difference.

From Fig. 14 it can be seen that there is a good correlation between the corrosion rate of embedded steel and the concentration of sulphides in the pore solution for the concretes studied. As expected [14], the corrosion rate generally decreased with the 
Fig. 8 Corrosion rates calculated from the gravimetric mass loss of steel and corrosion of the anodic steel bars at the end of the exposure regime

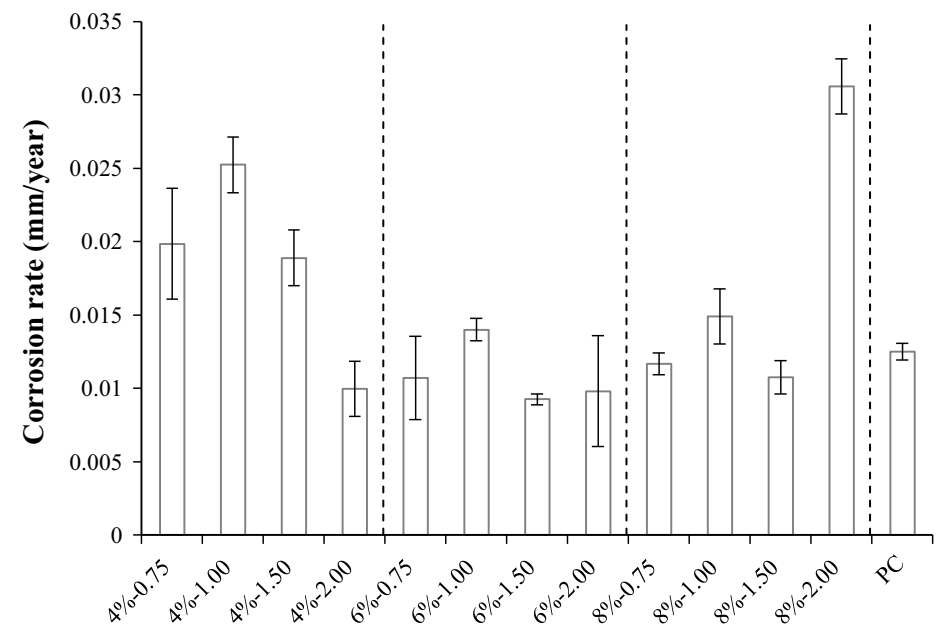

(a) corrosion rate
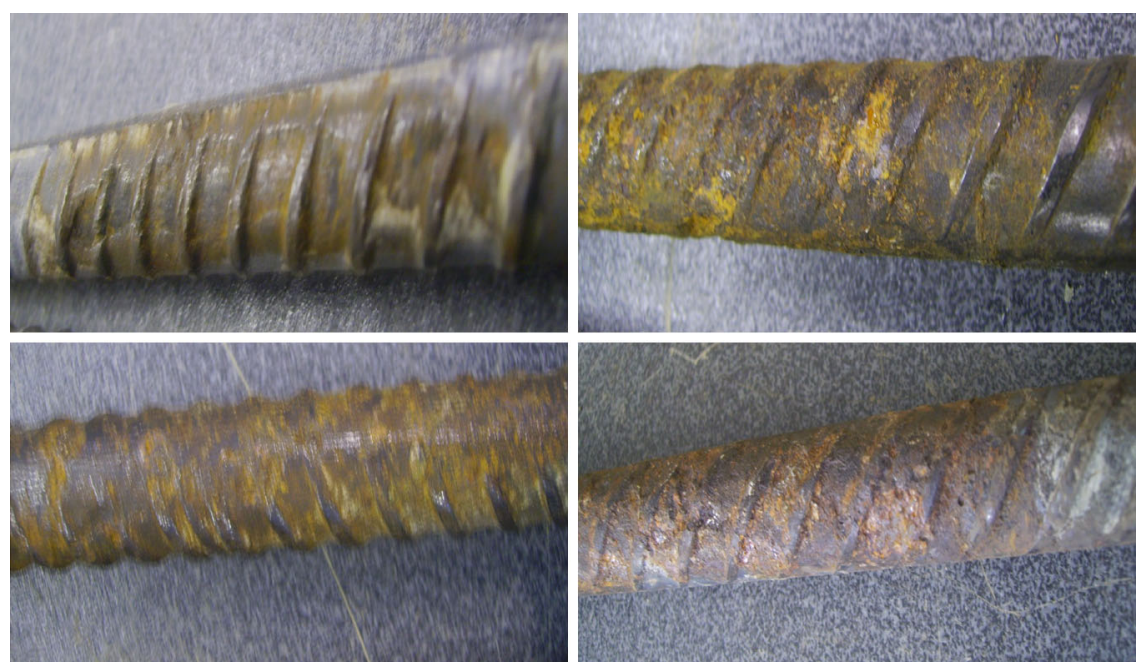

(b) Corrosion of the anodic steel bar (top left is PC concrete and the other ones are AAS concretes) increase of the concentration of sulphides due to the reducing environment provided by sulphides.

\section{Conclusion}

On the basis of the mixes studied and test methods applied for the characterisation of chloride transport and its resulting corrosion of the steel bars in the AAS concretes, the following conclusions have been drawn:

1. The AAS concretes had higher total chloride content at the surface than that of the PC concrete. Greater ionic exchange between the chlorides and the hydroxyl ions and the possibly enhanced chloride binding at the surface of the AAS concretes have been identified as the possible reasons.

2. Compared to the PC concrete, the AAS concretes were found to have lower chloride diffusivity. The better pore structure, the possibly stronger interaction between hydration products and the accompanying sodium cations and the improved chloride binding for the AAS concretes are considered to be the reason for this.

3. The non-steady state diffusion coefficient, $D_{\text {nssd }}$, of the AAS concretes was found to be influenced 
by both $\mathrm{Na}_{2} \mathrm{O} \%$ and Ms. An increase in $\mathrm{Na}_{2} \mathrm{O} \%$ from 4 to 8 resulted in a decrease in $D_{\text {nssd }}$. Ms of 1.50 proved to be the optimum to give the lowest $D_{\text {nssd }}$. This is in agreement with their effect on the hydration of AAS.

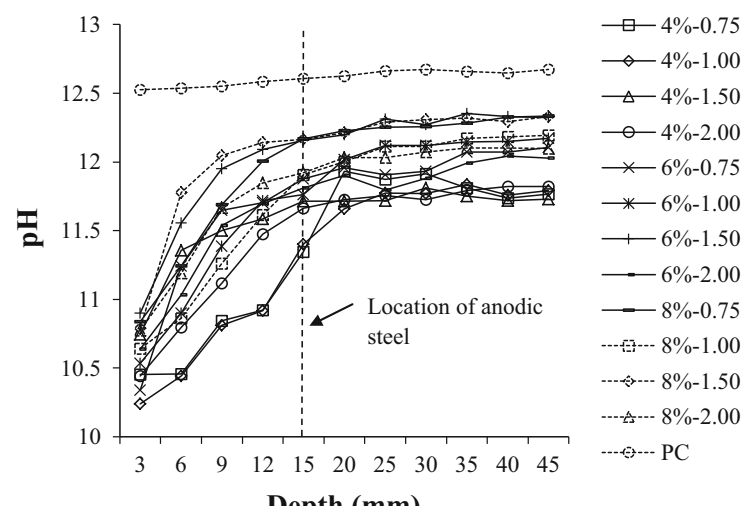

Fig. $9 \mathrm{pH}$ profiles determined at the end of the chloride ponding exposure regime
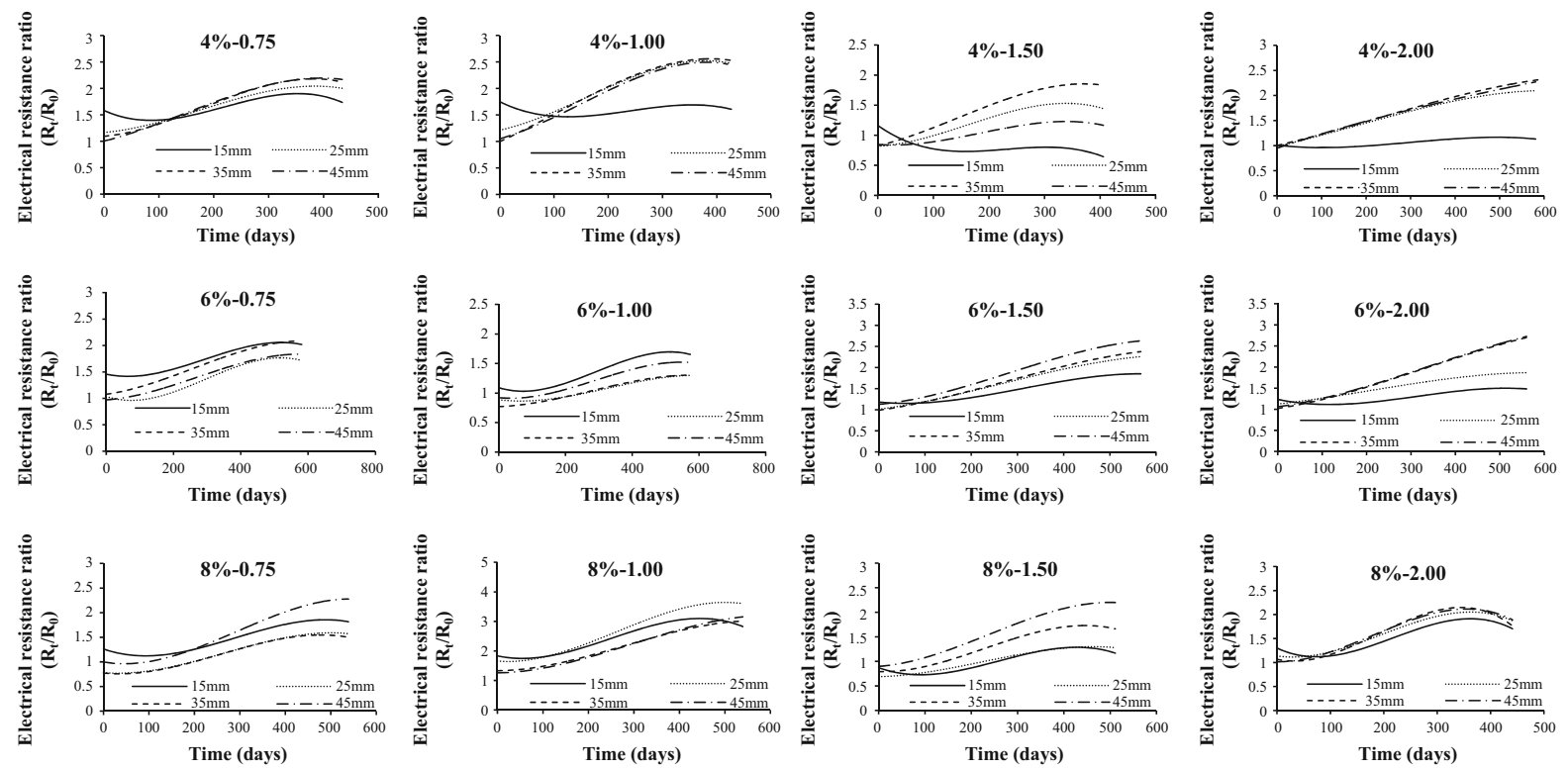

4. The corrosion rate of the steel bars in the AAS concretes was comparable to that observed in the PC concrete under the intermittent chloride ponding regime. It should be noted that AAS concretes were subjected to longer ponding

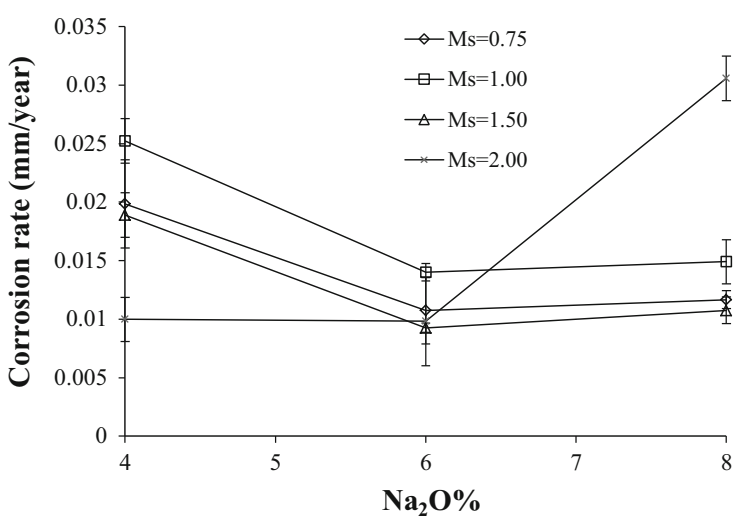

Fig. 11 Effect of $\mathrm{Na}_{2} \mathrm{O} \%$ on the corrosion rate

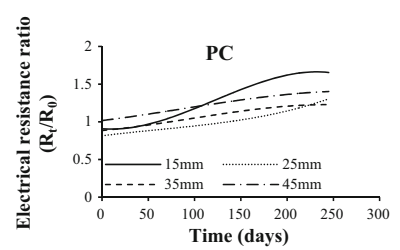

Fig. 10 Change in the ratio of electrical resistance during chloride ponding test $\left(R_{(t, x)}\right.$ is the resistance at any time ' $t$ ' for each depth $(x)$, $R_{0}$ is the resistance at time ' 0 ' for the depth of $45 \mathrm{~mm}$ ) 


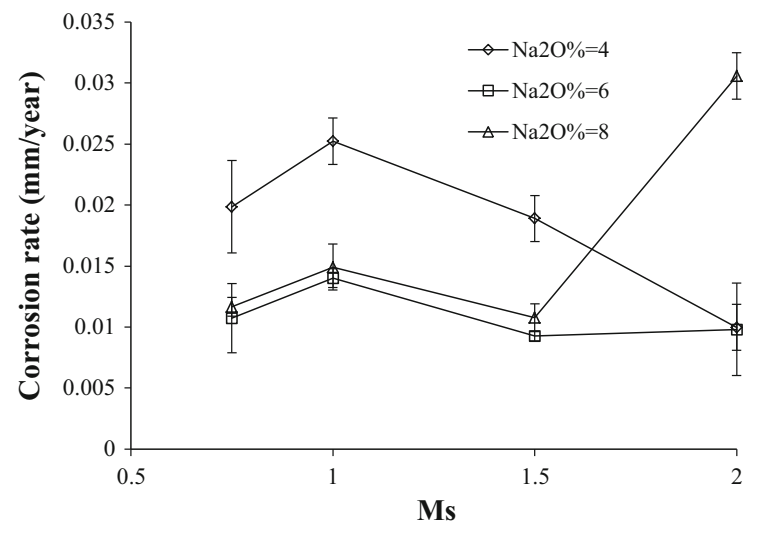

Fig. 12 Effect of Ms on the corrosion rate

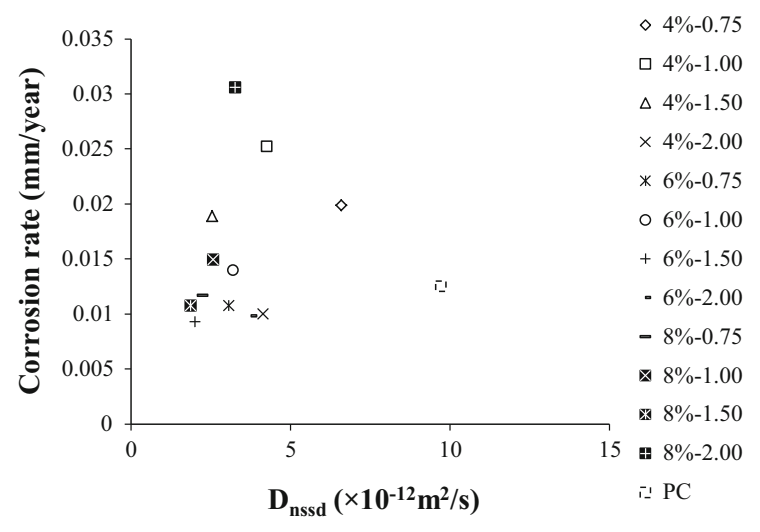

Fig. 13 Relationship between the corrosion rate and the nonsteady state chloride diffusion coefficient

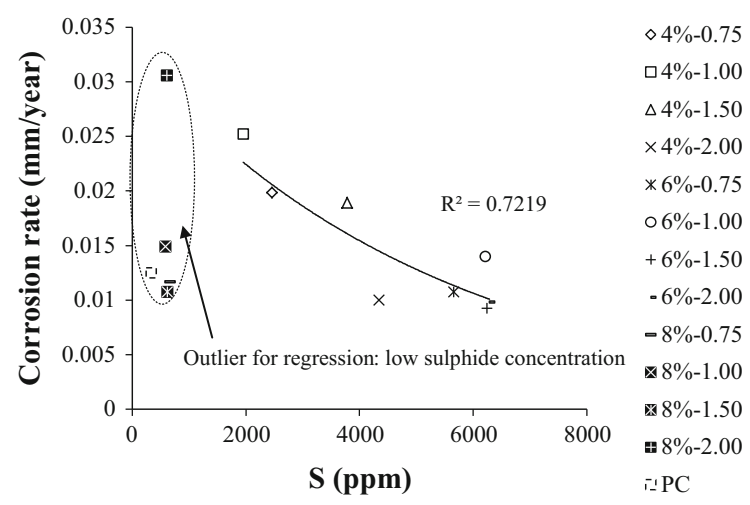

Fig. 14 Relationship between the corrosion rate and the sulphide concentration

(exposure) duration, therefore a direct comparison is not possible. Nevertheless, $6 \% \mathrm{Na}_{2} \mathrm{O}$ and modulus of 1.5 seems optimum for reducing the rate of corrosion.
5. The corrosion rate of the steel bars in the AAS concretes was significantly influenced by the free sulphide concentration.

6. The effect of $\mathrm{Na}_{2} \mathrm{O} \%$ and $\mathrm{Ms}$ on the corrosion rate of the steel bars in the AAS concretes was similar to their effect on the $D_{\text {nssd, but the }}$ reduction of the corrosion rate with the increase of $\mathrm{Na}_{2} \mathrm{O} \%$ from 6 to 8 was not clear. In addition to the hydration of AAS, the additional effect of sulphides concentration was thought to be the reason for such a trend for the corrosion rate of the embedded steel bars.

Acknowledgments The authors express their thanks to the sponsorship by UK-China Science Bridge project (EPSRC/ G042594/1), China Scholarship Council studentship and internal funds provided by Queen's University Belfast. The slag used in this research was supplied by Civil and Marine Ltd. Comments and suggestions by Prof. Luping Tang of Chalmers University of Technology are also greatly acknowledged.

Open Access This article is distributed under the terms of the Creative Commons Attribution 4.0 International License (http:// creativecommons.org/licenses/by/4.0/), which permits unrestricted use, distribution, and reproduction in any medium, provided you give appropriate credit to the original author(s) and the source, provide a link to the Creative Commons license, and indicate if changes were made.

\section{References}

1. Shi C, Krivenko PV, Roy D (2006) Alkali-activated cements and concretes. Taylor \& Francis, London

2. Puertas F, Fernandez-Jimenez A, Blanco-Varela MT (2004) Pore solution in alkali-activated slag cement pastes. Relation to the composition and structure of calcium silicate hydrate. Cem Concr Res 34:139-148

3. Broomfield JP (2007) Corrosion of steel in concrete: understanding, investigation and repair, 2 nd edn. Taylor \& Francis, London

4. Tang L, Nilsson L-O, Basheer PAM (2012) Resistance of concrete to chloride ingress testing and modelling. Spon Press, New York

5. Buenfeld NR, Glass GK, Hassanein AM, Zhang J-Z (1998) Chloride transport in concrete subjected to electrical field. J Mater Civ Eng 10:220-228

6. Zhang T, Gjorv OE (1996) Diffusion behavior of chloride ions in concrete. Cem Concr Res 26:907-917

7. Tang L (1999) Concentration dependence of diffusion and migration of chloride ions Part 1. Theoretical considerations. Cem Concr Res 29:1463-1468

8. Nachbaur L, Nkinamubanzi P-C, Nonat A, Mutin J-C (1998) Electrokinetic properties which control the coagulation of silicate cement suspensions during early age hydration. J Colloid Interface Sci 202:261-268 
9. Tritthart J (1989) Chloride binding in cement II. The influence of the hydroxide concentration in the pore solution of hardened cement paste on chloride binding. Cem Concr Res 19:683-691

10. Shi C (1996) Strength, pore structure and permeability of alkali-activated slag mortars. Cem Concr Res 26:1789-1799

11. Rodriguez E, Bernal S, Gutiérrez de Gutiérrez R, Puertas F (2008) Alternative concrete based on alkali-activated slag. Mater de Constr 58(291):53-67

12. Al-Otaibi S (2008) Durability of concrete incorporating GGBS activated by water-glass. Constr Build Mater 22(10):2059-2067

13. Schuring J, Schulz HD, Fischer WR, Bottcher J, Duijnisveld W (1999) Redox, fundamentals, processes and applications. Springer, New York

14. Shoesmith DW, Taylor P, Bailey MG, Ikeda B (1978) Electrochemical behaviour of iron in alkaline sulphide solutions. Electrochim Acta 23:903-916

15. Glasser FP (1991) Chemical, mineralogical, and microstructural changes occurring in hydrated slag-cement blends. Mater Sci Concr II:41-81

16. Holloway M, Sykes JM (2005) Studies of the corrosion of mild steel in alkali-activated slag cement mortars with sodium chloride admixtures by a galvanostatic pulse method. Corros Sci 47(12):3097-3110

17. Gomez RT, Aperador W, Vera E, Mejía de Gutiérrez R, Ortiz C (2010) Study of steel corrosion embedded in AAS concrete under chlorides. Dyna 77(164):52-59

18. NT BUILD 443 (1995) Concrete, hardened: accelerated chloride penetration

19. BS EN 15167-1 (2006) Ground granulated blast furnace slag for use in concrete, mortar and grout-Part 1 Definitions, specifications and conformity criteria

20. BS EN 197-1 (2000) Cement—Part 1: Composition, specifications and conformity criteria for common cements

21. Yang C, Pu X (1993) Retarder of alkali activated slag, Chinese patent, 91108316.2

22. BS EN 206-1 (2000) Concrete -Part 1: Specification, performance, production and conformity

23. BS 1881-125 (1986) Testing concrete -Part 125: Methods for mixing and sampling fresh concrete in the laboratory

24. BS EN 12350-2 (2009) Testing fresh concrete Part 2: Slump-test

25. BS EN 12350-3 (2009) Testing hardened concrete Part 3: Compressive strength of test specimens

26. NT BUILD 492 (1999) Concrete, mortar and cement-based repair materials: chloride migration coefficient from nonsteady-state migration experiments

27. RILEM TC 178-TMC (2002) Testing and modelling chloride penetration in concrete' analysis of total chloride content in concrete Recommendation. Mater Struct 35:583-585

28. RILEM TC 178-TMC (2002) Testing and modelling chloride penetration in concrete' analysis of water soluble chloride content in concrete recommendation. Mater Struct 35:586-588
29. Ma Q (2013) Chloride transport and chloride induced corrosion of steel reinforcement in sodium silicate solution activated slag concrete, Ph.D thesis, Queen's University Belfast, U. K

30. Tang L (2005) Guideline for practical use of methods for testing the resistance of concrete to chloride ingress, Chlortest Report

31. BS 8500-1 (2006) Concrete-complementary British Standard to BS EN 206-1-part 1: method of specifying and guidance for the specifier

32. Allahverdi A, Shaverdi B, Najafi KE (2010) Influence of sodium oxide on properties of fresh and hardened paste of alkali-activated blast-furnace slag. Int $\mathrm{J}$ Civil Eng 8(4):304-314

33. Karahan O, Yakupoglu A (2011) Resistance of alkali-activated slag mortar to abrasion and fire. Adv Cem Res 23(6):289-297

34. Krizan D, Zivanovic B (2002) Effects of dosage and modulus of water glass on early hydration of alkali-slag cements. Cem Concr Res 32(8):1181-1188

35. Neto AMA, Cincotto MA, Repette W (2008) Drying and autogenous shrinkage of pastes and mortars with activated slag cement. Cem Concr Res 38(4):565-574

36. Bernal SA, Provis JL, Rose V, de Mejía Gutierrez R (2011) Evolution of binder structure in sodium silicate-activated slag-metakaolin blends. Cem Concr Compos 33(1):46-54

37. Basheer PAM, Gilleece PRV, Long AE, Mc Carter WJ (2002) Monitoring electrical resistance of concretes containing alternative cementitious materials to assess their resistance to chloride penetration. Cem Concr Compos 24(5):437-449

38. Polder RB, Peelen WHA (2002) Characterisation of chloride transport and reinforcement corrosion in concrte under cyclicwetting and drying by electrical resistivity. Cem Concr Compos 24(5):427-435

39. Whittington HW, McCarter J, Forde MC (1981) The conduction of electricity through concrete. Mag Concr Res 33(114):48-60

40. Wang SD, Scrivener KL (1995) Hydration products of alkali activated slag cement. Cem Concr Res 25(3):561-571

41. Hong S-Y, Glasser FP (2002) Alkali sorption by C-S-H and C-A-S-H gels: Part II. Role of alumina. Cem Concr Res 32:1101-1111

42. Chen W, Brouwers HJH (2011) A method for predicting the alkali concentrations in pore solution of hydrated slag cement paste. J Mater Sci 46:3622-3631

43. Castellote M, Andrade C, Alonso C (2000) Phenomenological mass-balance-based model of migration tests in stationary conditions application to non-steady-state tests. Cem Concr Res 30(12):1885-1893

44. Page CL (1975) Mechanism of corrosion protection in reinforced concrete marine structures. Nature 258:514-515 